\title{
Climate change adaptation of coffee production in space and time
}

\author{
Peter Läderach $^{1,2}$ • Julian Ramirez-Villegas ${ }^{2,3,4}$ • \\ Carlos Navarro-Racines ${ }^{2,3} \cdot$ Carlos Zelaya $^{1} \cdot$ \\ Armando Martinez-Valle ${ }^{1} \cdot$ Andy Jarvis ${ }^{2,3}$
}

Received: 18 September 2015 / Accepted: 26 August 2016/Published online: 26 October 2016

(C) The Author(s) 2016. This article is published with open access at Springerlink.com

\begin{abstract}
Coffee is grown in more than 60 tropical countries on over 11 million ha by an estimated 25 million farmers, most of whom are smallholders. Several regional studies demonstrate the climate sensitivity of coffee (Coffea arabica) and the likely impact of climate change on coffee suitability, yield, increased pest and disease pressure and farmers' livelihoods. The objectives of this paper are (i) to quantify the impact of progressive climate change to grow coffee and to produce high quality coffee in Nicaragua and (ii) to develop an adaptation framework across time and space to guide adaptation planning. We used coffee location and cup quality data from Nicaragua in combination with the Maxent and CaNaSTA crop suitability models, the WorldClim historical data and the CMIP3 global circulation models to predict the likely impact of climate change on coffee suitability and quality. We distinguished four different impact scenarios: Very high (coffee disappears), high (large negative changes), medium (little negative changes) and increase (positive changes) in climate suitability. During the Nicaraguan coffee roundtable, most promising adaptation strategies were identified, which we then used to develop a two-dimensional adaptation framework for coffee in time and space. Our analysis indicates that incremental adaptation may occur over
\end{abstract}

This article is part of a Special Issue on "Climate change impacts on ecosystems, agriculture and smallholder farmers in Central America" edited by Camila I. Donatti and Lee Hannah.

Electronic supplementary material The online version of this article (doi:10.1007/s10584-016-1788-9) contains supplementary material, which is available to authorized users.

Peter Läderach

p.laderach@cgiar.org

International Center for Tropical Agriculture (CIAT), Managua, Nicaragua

2 CGIAR Research Program on Climate Change, Agriculture and Food Security (CCAFS), Cali, Colombia

3 International Center for Tropical Agriculture (CIAT), Cali, Colombia

4 School of Earth and Environment, University of Leeds, Leeds, UK 
short-term horizons at lower altitudes, whereas the same areas may undergo transformative adaptation in the longer term. At higher elevations incremental adaptation may be needed in the long term. The same principle and framework is applicable across coffee growing regions around the world.

Keywords Climate change -Adaptation - Spatial modeling $\cdot$ Nicaragua Incremental adaptation . Transformative adaptation

\section{Introduction}

The global climate has changed over the past century and is projected to continue changing throughout the twenty-first century (IPCC 2014). Global circulation models (GCMs) all point to higher mean temperatures and changes in precipitation regimes.

Central America is affected by droughts, hurricanes and the El Niño-southern oscillation (ENSO) phenomena (CEPAL 2011) and is therefore one of the most exposed regions to climate change and variability (Giorgi 2006). A global evaluation of the impacts of extreme weather events between 1993 and 2012 ranks three countries in the region among the top ten (Honduras is ranked first, Nicaragua fourth and Guatemala tenth) on the Global Climate Risk Index (Kreft and Eckstien 2013).

Nicaragua has already experienced substantial climate change, which contributed to stagnating yields for maize (Zea mays) and bean (Phaseolus vulgaris), and its coffee sector (Coffea arabica) is, after El Salvador, the most exposed globally to progressive climate change (Gourdji et al. 2015; Ovalle-Rivera et al. 2015).

Coffee is grown in more than 60 tropical countries (Waller et al. 2007) on over 11 million ha by an estimated 25 million farmers, mostly smallholders (Waller et al. 2007). Coffee production is a significant contributor to agricultural GDP and export earnings in Latin America. In Nicaragua, coffee production accounts for $18.2 \%$ (MAGFOR 2012) and $17 \%$ (ICO 2013) of GDP, respectively, and is considered a nationally strategic activity, since it is grown on 127,000 ha, giving labor to 44,500 families (MAGFOR 2012). Furthermore, agroforestry systems, commonly used in the tropics to produce coffee, provide important environmental benefits such as biodiversity (Jha et al. 2014), carbon accumulation (van Rikxoort et al. 2014), water storage and erosion control (Wardle et al. 2011) .

Farmers who grow annual crops have the flexibility to select among the group of crops suited to their location. The selection is based on criteria that include sustenance, market dynamics, productivity, cultural preferences, level of investment and risk avoidance. Market factors can drive rapid changes in cropping systems, which can be both a problem and an opportunity. In contrast, growers of perennial crops, such as coffee, which require longer -lead times for both farmers and business partners to make changes, do not have this flexibility. Decisions coffee growers make today may take years to take effect, due to the long lead time of agroforestry systems, as they take years to be established compared to annual crops.

Urgent action is required to address the issues of future changes in climate as they apply to perennial cropping systems, as previously shown for coffee (Baca et al. 2014; Bunn et al. 2014; Craparo et al. 2015; Garcia et al. 2014; Ovalle-Rivera et al. 2015) and cocoa (Läderach et al. 2013; Schroth et al. 2016a, b). In this paper, our objectives are (i) to quantify the impact 
of climate change on the suitability to grow coffee (MaxEnt analysis) and to produce high quality coffee (CaNaSTA analysis) and (ii) to develop an adaptation framework across time and space to guide adaptation planning in Nicaraguan coffee systems.

\section{Methods}

In the following sub-sections, we first describe the sampling design, including coffee presence and quality data collection. We then describe the input of current and future (2050) climate data and explain climate suitability modeling and validation. Finally, we describe how promising adaptation strategies were identified through a national coffee roundtable.

\subsection{Sampling design, coffee presence and quality data}

Coffee-growing areas in Nicaragua were mapped by Valerio-Hernández (2002) but without distinguishing between Arabica and Robusta coffee. The map shows that coffee is produced at Nicaraguan altitudes of 100-1400 masl. According to CAFENICA (Cooperativas de Pequeños Productores de Café de Nicaragua) experts, Arabica coffee grows between 500 and 1400 masl. In contrast, below 500 masl most producers grow Robusta coffee. Robusta coffee plants have different eco-physiological requirements than Arabica coffee plants and would have introduced error to the analysis, as Coffea arabica (Arabica coffee) and Coffea canephora (Robusta coffee) are two different species. Therefore, we only used information on Arabica coffee and sites with elevations between 500 and 1400 masl. We extracted the geographical coordinates of coffee farms in the 3155 polygons (area of approximately $1200 \mathrm{~km}^{2}$ ) identified as growing coffee that represent the Nicaraguan coffee zone. We obtained coordinates, at 30 arc-second spatial resolution (approximately $1 \mathrm{~km}$ at the equator), for a total of 4919 pixels that show where coffee is currently present.

For the coffee quality analysis, we used the data of a recent PDO project (FUNICA 2012). We designated the population of farms for our model to be the coffee-producing departments of Estelí, Madriz and Nueva Segovia, which contain $87 \%$ of Nicaragua's coffee growers. From these we selected a statistical subset of 295 farms, which represented $0.66 \%$ of the 44,519 coffee farms in Nicaragua. FUNICA harvested ripe coffee cherries from each of these farms. The cherries were de-pulped, fermented and dried according to a standardized protocol (Läderach et al. 2011). A panel of 15 cuppers $^{1}$ assessed the quality of the samples of coffee from each farm according to the Specialty Coffee Association of America (SCAA) standards (Lingle 2001). The sensory attributes evaluated were acidity and flavor, which are those for which Nicaragua's coffee is famous for. Each attribute was scored from 1 to 10 depending on its intensity (Lingle 2001). For the CaNaSTA modeling (see section 2.4). Flavor is self-explanatory while acidity is the intensity of acidic sensation in the mouth.

\footnotetext{
${ }^{1}$ The cuppers were experts from the cupping laboratories of the Asociación de Cafés Especiales de Nicaragua (ACEN), CISA Exportadora, Asociación de Cooperativas de Pequeños Productores de Café de Nicaragua (CAFENICA) and Promotora de Desarrollo Cooperativo de Las Segovias, Sociedad Anónima (PRODECOOP, S.A.).
} 


\subsection{Historical climate data}

We obtained historical climate data of monthly total precipitation and mean monthly minimum and maximum temperatures from the WorldClim database (Hijmans et al. 2005 ) at 30 arcsecond resolution. Hijmans et al. (2005) calculated means for 1960-1990 from weather stations with more than 10 years of data. The data for precipitation were from 47,554 locations and for temperature, from 14,835 locations globally. The WorldClim database includes 225 stations for precipitation and 18 stations for temperature for Nicaragua.

The WorldClim database also includes 19 bioclimatic variables (Table 1), which are more biologically meaningful (Busby 1991) for use in ecological niche modeling (e.g., BIOCLIM, GARP) than the monthly temperature and precipitation data. They "represent annual trends

Table 1 Bioclimatic variables. Nineteen bioclimatic variables used for the analysis, representing mean and extreme conditions. The table shoes the average current and future values for the bioclimatic variables for the 19 GCMs (CMIP3) under the SRES-A2 emissions scenario by 2050s (2040-2069) across the coffee growing areas in Nicaragua

\begin{tabular}{|c|c|c|c|}
\hline ID & Variable & $\begin{array}{l}\text { Current mean } \\
\text { (Standard Deviation) }^{\mathrm{a}}\end{array}$ & $\begin{array}{l}\text { 2050s mean } \\
\text { (Standard Deviation) }^{\mathrm{b}}\end{array}$ \\
\hline Bio 1 & Annual mean temperature & $21.58(1.34)$ & $23.89(0.78)$ \\
\hline Bio 2 & $\begin{array}{l}\text { Mean diurnal range } \\
\text { (Mean of monthly } \\
\quad(\max \text { temp - min temp)) }\end{array}$ & $104.1(4.37)$ & $109.21(18.65)$ \\
\hline Bio 3 & Isothermality (Bio2/Bio7) $\left({ }^{\mathrm{a}} 100\right)$ & $72.11(1.06)$ & $72.06(2.09)$ \\
\hline Bio 4 & $\begin{array}{l}\text { Temperature seasonality } \\
\quad\left(\text { standard deviation }{ }^{\mathrm{a}} 100\right)\end{array}$ & $935.01(95.53)$ & $1060.08(155.72)$ \\
\hline Bio 5 & Maximum temperature of warmest month & $28.76(1.53)$ & $31.38(2.00)$ \\
\hline Bio 6 & Minimum temperature of coldest month & $14.42(1.38)$ & $16.36(0.62)$ \\
\hline Bio 7 & $\begin{array}{l}\text { Temperature annual range } \\
\quad(\text { Bio5 - Bio6) }\end{array}$ & $14.34(0.61)$ & $15.03(2.26)$ \\
\hline Bio 8 & Mean temperature of wettest quarter & $21.91(1.25)$ & $24.33(0.86)$ \\
\hline Bio 9 & Mean temperature of driest quarter & $21.44(1.40)$ & $23.65(0.89)$ \\
\hline Bio 10 & Mean temperature of warmest quarter & $22.63(1.35)$ & $25.00(0.88)$ \\
\hline Bio 11 & Mean temperature of coldest quarter & $20.23(1.38)$ & $22.35(0.78)$ \\
\hline Bio 12 & Annual precipitation & $1741.6(325.29)$ & $1645.82(167.45)$ \\
\hline Bio 13 & Precipitation of wettest month & $278.65(41.98)$ & $277.46(20.53)$ \\
\hline Bio 14 & Precipitation of driest month & $23.99(10.57)$ & $22.24(3.11)$ \\
\hline Bio 15 & $\begin{array}{l}\text { Precipitation seasonality } \\
\quad \text { (coefficient of variation) }\end{array}$ & $65.71(9.07)$ & $66.53(3.02)$ \\
\hline Bio 16 & Precipitation of wettest quarter & $758.95(119.23)$ & $726.46(69.70)$ \\
\hline Bio 17 & Precipitation of driest quarter & $88.25(32.76)$ & $86.53(9.31)$ \\
\hline Bio 18 & Precipitation of warmest quarter & $428.23(103.38)$ & $429.32(85.74)$ \\
\hline Bio 19 & Precipitation of coldest quarter & $192.31(63.34)$ & $206.82(45.46)$ \\
\hline
\end{tabular}

${ }^{\text {a }}$ Average (and Standard Deviation) of the bioclimatic values at know coffee production locations for the current climate

${ }^{\mathrm{b}}$ Average of the bioclimatic values of the 19 GCM's (CMIP3) SRES A2 at know coffee production locations under future climate (2050). Standard Deviation is the deviation of the 19 GCM's SRES A2, averaged between the evidence points 
(e.g., mean annual temperature, annual precipitation), seasonality (e.g., annual range in temperature and precipitation), and extreme or limiting environmental factors (e.g., temperature of the coldest and warmest month, and precipitation during the wettest and driest quarters)" (WorldClim, 2015).

We clipped climate surfaces for each bioclimatic variable for Nicaragua from the original WorldClim dataset. We then used Arc/Info (ESRI, version 9.2) to extract the data corresponding to each of the locations in the study from the WorldClim gridded data.

\subsection{Future climate}

The Intergovernmental Panel on Climate Change (IPCC) Fourth Assessment Report (AR4) was based on data from 19 global climate models (GCMs) (IPCC 2014). The spatial resolution of the GCMs output (1 degree, about $110 \mathrm{~km}$ at the equator) is often too coarse to analyze the impacts of climate change in agriculture. This is especially a problem in heterogeneous landscapes such as the Nicaraguan coffee zone, where one cell can cover the entire width of the mountain range.

We therefore need downscaled GCM outputs if we are to project the likely impacts of climate change on agriculture. We used statistical downscaling of GCM output to produce 1-km resolution surfaces of the mean monthly maximum and minimum temperatures and monthly precipitation (Hijmans et al. 2005 ; Ramírez and Jarvis 2010). The delta method corrects the mean bias in the monthly GCM projections by first computing the change (or delta-difference between the transient future and historical climate in the GCM simulation), then interpolating this change and finally adding it onto the historical observations (i.e. WorldClim). In all cases, we used the IPCC scenario SRES-A2 ("business as usual") (SRES 2000). The data we used are available on the CCAFS Climate portal ( 2016) (URL: www.ccafs-climate.org).

\subsection{Climate suitability analysis}

We used the niche models MaxEnt (maximum entropy) and CaNaSTA (Crop Niche Selection for Tropical Agriculture), which can predict crop suitability (MaxEnt) and performance (CaNaSTA), such as quality, over large areas with limited input data (Oberthür et al. 2011; Ovalle-Rivera et al. 2015; Whitsed et al. 2010) to project the impact of climate change on coffee suitability and quality. All the analyses were conducted using raster format and WGS84 projection.

MaxEnt has been used to analyze the impact of climate change on coffee at regional and global scales (Baca et al. 2014; Bunn et al. 2014; Davis et al. 2012; Ovalle-Rivera et al. 2015; Schroth et al. 2009). Here we use it for a more restricted scale in Nicaragua. Maximum entropy (MaxEnt) allows the user to make predictions or draw inferences from incomplete information (Phillips et al. 2006). Similar to logistic regression, MaxEnt weights each environmental variable (explanatory variables) starting with a uniform distribution of probabilities. It then iteratively alters one weight at a time to maximize the likelihood of reaching the optimum probability distribution to predict the response variables (coffee suitability). The probability distribution of the explanatory variables is then applied to the pixels with incomplete information (where no response variable is available) to predict the probability of coffee climate suitability for these areas. In MaxEnt we applied a logistic function to the output with the maximum set to 1 to give probability estimates 0-1 (Ovalle-Rivera et al. 2015). The inputs to the MaxEnt model were the coordinates of known coffee production areas and spatial layers of the 19 bioclimatic variables for current and 2050 climate conditions. The outputs were spatial layers of climate suitability to produce coffee currently and in 2050. 
We used CaNaSTA to project the impact of climate change on coffee quality. While MaxEnt operates only with coordinates, CaNaSTA uses both coordinates and performance indicators. It was therefore more useful to evaluate the effect of climate change on the beverage attributes of acidity and flavor. Oberthür et al. (2011) used CaNaSTA to subdivide the PDO of Colombian coffee. CaNaSTA (O'Brien et al. 2004; Whitsed et al. 2011) employs Bayesian statistics to define prior and conditional probability distributions and to combine these to calculate posterior probabilities for each possible outcome. The input to CaNaSTA were beverage quality (flavor and acidity) attributes for the sampled sites and spatial layers of the 19 bioclimatic variables for current and 2050 climate conditions. The output were spatial layers of suitability to produce the respective coffee quality attributes currently and in 2050. We analyzed the cupping scores of the acidity and flavor attribute, which are average values between 0 and 1 . We overlaid the CaNaSTA results with a filter of certainty of $80 \%$, as previously recommended, and tested to perform coffee quality analysis (Oberthür et al. 2011 and Whitsed et al. 2011).

We refer to 'climatic suitability' of a site as the probability that Arabica coffee grows well there because of favorable climate conditions (Ovalle-Rivera et al. 2015), for the case of the MAXENT analysis. In the case of the CaNaSTA model and quality projection, it refers to the probability that the climate associated to a particular site will produce coffee with high acidity and flavor as determined by cupping. We calibrated the climate suitability for coffee, using the current distribution of coffee in Nicaragua, as follows: Suitability lower than $40 \%$ refers to marginal areas, where today only very little or no coffee is grown; suitability of 40-60\% refers to marginal areas that are currently in coffee production, but where farmers already suffer from lower yield, increased pest and disease pressure and decreased quality; suitability of $60-80 \%$ refers to main coffee growing areas; and suitability of 80-100\% refers to areas at higher altitudes that are being rewarded by the market with premiums for high-grown coffee.

MaxEnt and CaNaSTA predict the probability that areas have suitable climates, which may differ from where coffee is actually grown because of the many factors that influence land use. Furthermore, future climatically suitable areas may not grow coffee because they are urbanized, are protected areas or are used in different cropping systems.

Demand on the world market and the price of coffee also affect where coffee is grown. Areas predicted to have low climate suitability in the future might still produce coffee if market prices are high. A possible scenario is increasing demand and therefore increased coffee marked prices coupled with less suitable area available, leading to increased prices.

\subsection{CaNaSTA and MaxEnt model validation}

Using the 4919 presence points, we ran MaxEnt 25 times, using $75 \%$ of the points (3689) for model training and the remaining $25 \%$ for model testing in each run. We used the default settings, which allowed the complexity of the model to vary depending on the number of data points used (see Phillips et al. 2006; Phillips and Dudík 2008; Warren and Seifert 2011). We used two measures to assess model skill: the area under the receiver operating characteristic curve (AUC) (Peterson et al. 2008) and the maximum possible Cohen's kappa (kmax) (Manel et al. 2001; Liu et al. 2005). AUC is a widely used measure of species distributions models skill (Phillips et al. 2006; Elith et al. 2006; Barbet-Massin et al. 2012, and references therein), which measures the ability of the model to discriminate between presences and absences. High AUC values indicate a high discrimination power (i.e. low rates of false positives and false negatives) whereas AUC values near 0.5 indicate the model performs the same as a random prediction. Cohen's kappa is defined by the precision of the prediction in relation to a random prediction 
(Fielding and Bell 1997). A high kappa coefficient indicates that the prediction has low errors of omission (i.e. low rate of false negatives and high rates of true positives) and commission (i.e. low rates of false positives and high rates of true negatives). We calculated both measures using the whole area of Nicaragua as a fixed background area from which we drew 10,000 random pseudo-absences of coffee; that is, a fixed-area AUC (VanDerWal et al. 2009). We used two measures to guard against the caveats that can arise when the AUC is the only measure used to evaluate the model (see Lobo et al. 2008). We used the 25 model runs to project baseline (WorldClim) and future distributions (19 downscaled GCMs) on to their respective 30 arcsecond grids. This produced a total of 25 suitability predictions for the baseline and 475 (25 suitable predictions for the baseline X 19 GCMs) suitability predictions for the $2050 \mathrm{~s}$. We computed means and standard deviations of the suitability predictions and of the future changes in suitability (difference between future and baseline). These illustrate predicted changes and their associated uncertainties of both the MaxEnt estimations and the GCMs' predictions.

We followed a similar procedure with CaNaSTA. We split the 295 observations for sensory attributes at random, 25 times for each attribute, flavor and acidity. We used $75 \%$ of them (221) for training and $25 \%$ (74) for testing. For both the acidity and flavor characteristics, we fitted the model using the training data. We calculated the AUC and $k_{\max }$ (as in MaxEnt) for both the training and testing data. We drew 1414 random pseudo-absences based on a land-use map of Nicaragua (MAGFOR 2012), to assure equal sample representation for coffee and non coffeeproducing areas. In contrast to MaxEnt, runs of CaNaSTA cannot be automated. We therefore used the 357 data points to produce one single "best information available" model for each of the characteristics (which we hereafter call the final model). We projected this model onto the 19 future downscaled GCM projections. We then used the future projections to analyze future changes in suitability and estimate uncertainties caused by variations in the GCMs' projections.

\subsection{Participatory expert round table and literature review to identify adaptation options}

In September 2011 the Consejo Nacional del Café (CONACAFE) convened a one-day workshop to identify the most promising strategies for the coffee sector to adapt to climate change. Attendees comprised 173 experts from government, private sector and academia including researchers, technicians and farmers. Researchers presented information on the impact of climate change on the coffee sector, including the present study. The workshop then identified the most promising adaptation strategies, which were further complemented by a review of the literature (Rahn et al. 2013; Schroth et al. 2009; van Rikxoort et al. 2014) to complement the list of most promising adapation strategies in coffee. Both inputs where then used for the the development of the two-dimensional adaptation framework in time and space for coffee production, which suggests adaptation strategies for the four main impact scenarios.

\section{Results}

\subsection{Detailed climate change data for Nicaragua coffee areas}

The GCMs of the AR4 for the SRES-A2a (business as usual) emission scenario for 2050 continue showing a trend of increasing temperature and some decrease in precipitation for coffee-producing regions in Nicaragua (Fig. 1 and Table 1). The mean annual temperature will 


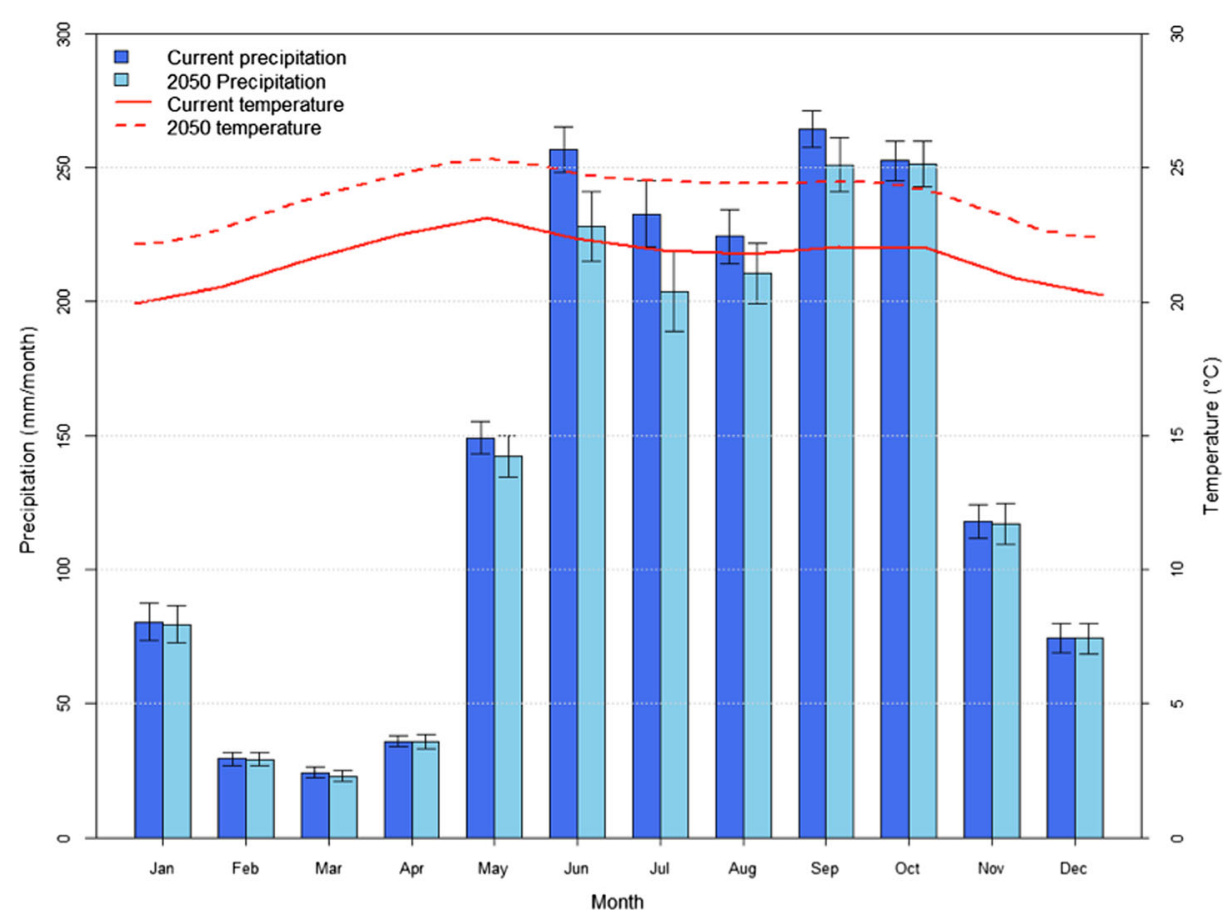

Fig. 1 Present-day and future (2050) projected monthly precipitation (bars) and mean temperature (lines) for coffee growing evidence sites used in analysis. Future values are averages of 19 GCMs under the SRES-A2 emissions scenario by 2050s (2040-2069)

likely increase by $2.2^{\circ} \mathrm{C}$, while the mean daily temperature range will increase from $10.4{ }^{\circ} \mathrm{C}$ to $10.6{ }^{\circ} \mathrm{C}$. Total annual average precipitation is projected to decrease from $1740 \mathrm{~mm}$ to $1610 \mathrm{~mm}$, while the maximum number of dry months will remain constant at 5 months.

\subsection{Impact of climate change on coffee suitability in Nicaragua}

At present, Arabica coffee has its maximum suitability at elevations 800-1200 masl, in the departments of Nueva Segovia, Jinotega, Estelí and western Matagalpa (Fig. 2). Uncertainties in the baseline were low, ranging between 0 and $5.2 \%$ of the full-projected suitability range. The areas with the highest uncertainty were in relatively low-elevation zones where coffee suitability was deemed marginal (data not shown here).

The predictions indicate a considerable reduction in the area suitable for Arabica coffee in Nicaragua by 2050 (Fig. 2). All future ensemble members project decreases in suitability in more than $90 \%$ of the growing areas. Particularly negative were the reductions in suitability at lower elevations 500-800 masl, where even the most optimistic ensemble member indicated a suitability reduction in the range $25-50 \%$ (Fig. 2). Uncertainties in the projection to 2050 were larger than in the baseline period. Most areas where coffee is projected to remain suitable in the future show that projected suitability decrease between 10 and $25 \%$ across ensemble members. This uncertainty was mostly driven by uncertainty in GCMs' projections of future climates. Previous studies on climate uncertainty and its effects on crop models have shown similar results (Challinor et al. 2005; Knutti and Sedlacek 2012). 

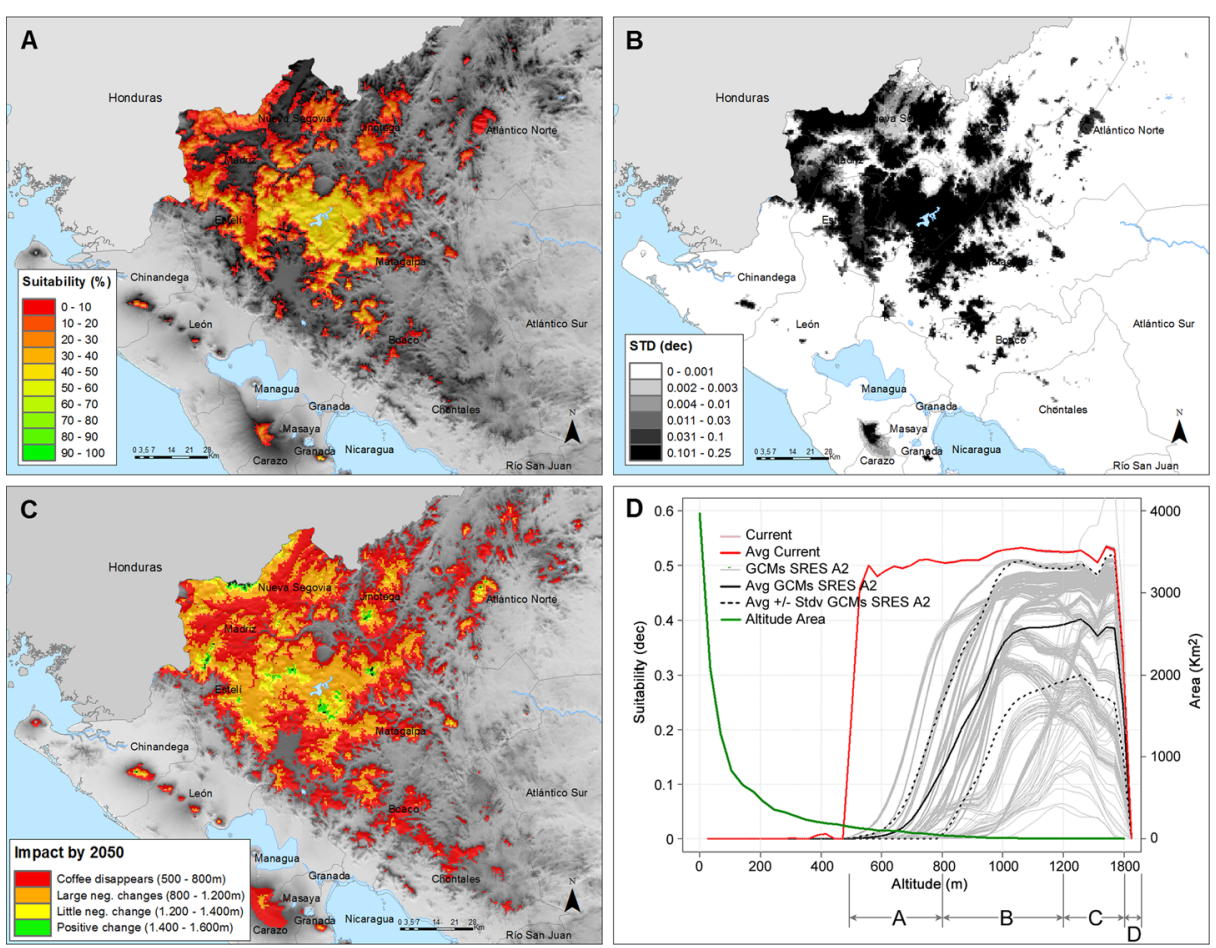

Fig. 2 Projected change in suitability and associated prediction uncertainties. a Average change in suitability of the 475 (19 GCMs $\times 25$ Maxent runs) future ensemble members; b standard deviation of the 475 ensemble members; $\mathbf{c}$ impacts by 2050 according to the altitudinal ranges; $\mathbf{d}$ current and future suitability versus altitude, area available at different altitudes and target areas for transformative adaptation ( $\mathbf{a}=$ coffee disappears), incremental adaptation $(\mathbf{b}=$ large negative and $\mathbf{c}=$ little negative changes $)$ and expansion $(\mathbf{d}=$ positive changes $)$

\subsection{Impact of climate change on coffee quality in Nicaragua}

We chose two attributes of coffee quality for their importance in consumer preference for specialty coffees: acidity and flavor. Both attributes are highly influenced by the environmental conditions of the sites where the coffee is grown. Moreover, the variation in these attributes is not random but is linked to climatic conditions.

By the 2050s the CaNaSTA analysis shows an overall decrease in suitability to produce coffee beans with high acidity and flavor (Fig. 3). At lower altitudes (500800 masl) the effect is very pronounced, whereas at mid altitudes (800-1400 masl) the suitability decreases slightly. However, at higher altitudes (1400-1600 masl) new areas in which no coffee is currently grown become suitable for production of high quality coffee by 2050 (see also Table 2).

We compared the pessimistic and optimistic GCMs to estimate their effects on flavor suitability (Fig. S4). The mean of the first quartile of the ensemble members shows decreases of $60-89 \%$ in suitability to produce coffee beans with high flavor (Fig. S4B). The mean of the third quartile (Fig. S4C), decreases only slightly in suitability $(20 \%)$ and some sites even increase in suitability. While some areas have very $(<6 \%)$ low standard deviations amongst model predictions (white areas in Fig. S4D), the contrary is true for higher elevation areas where suitability reductions are the largest (black areas in Fig. S4D). 


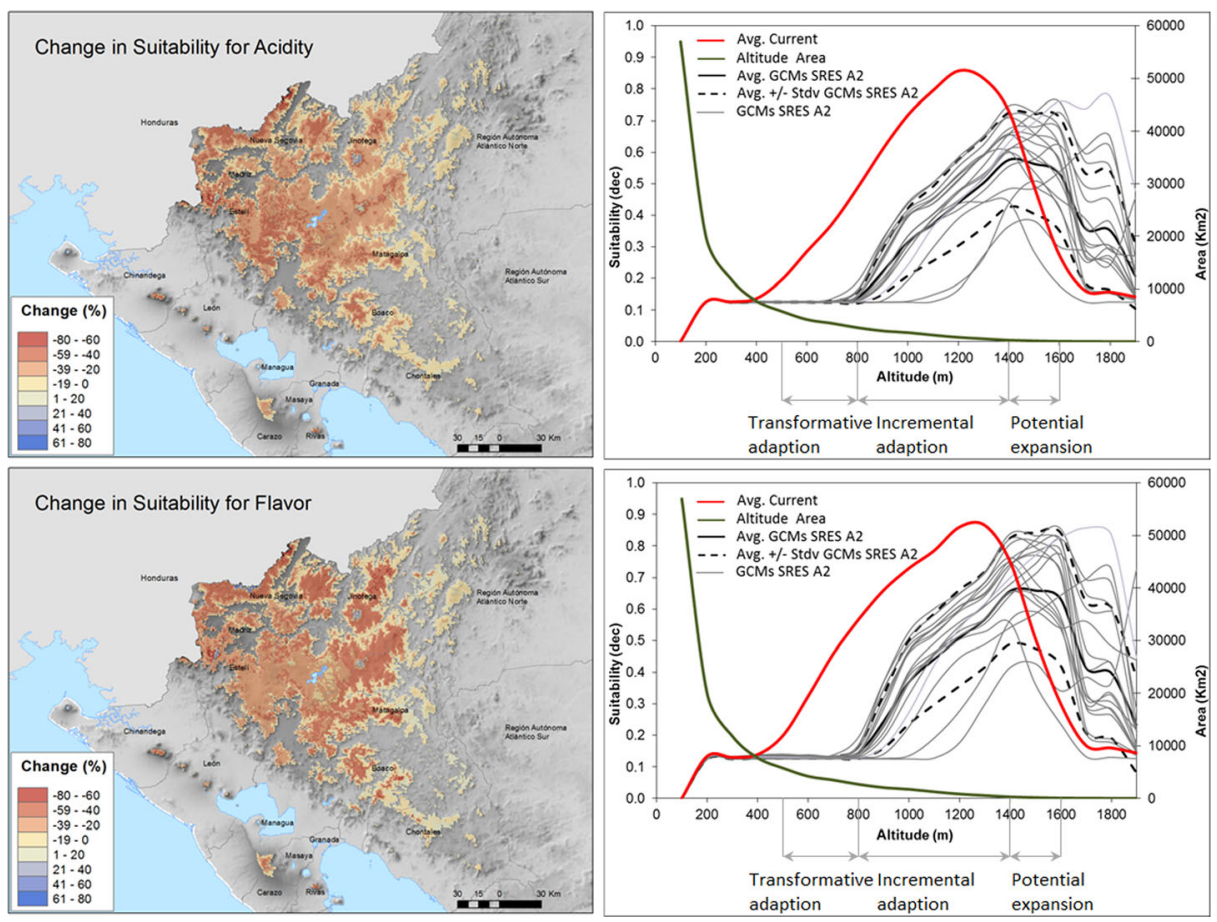

Fig. 3 Suitability change of flavor and acidity by 2050 as average of the 25 CaNaSTA ensemble members (left) and current and future quality suitability versus altitude, area available at different altitudes and target areas for transformative adaptation, incremental adaptation and expansion (right)

Acidity behaves very much the same as flavor. The first quartile of the ensemble members shows decreases greater $40 \%$ (Fig. S4B1). The third quartile of the ensemble members, however, shows little change (0-19\%) (Fig. S4C1). Again, the standard deviation shows that the projection of change is robust (standard deviation $<6 \%$ ) in most areas (Fig. S4D1). As for flavor, higher elevation areas where suitability reductions are the most significant show larger (standard deviation between 12 and $30 \%$ ) uncertainty.

The areas that have been selected as potential sites for the implementation of PDO (FUNICA 2012) occur in the third quartile of the ensemble members (Figure S4C and $\mathrm{S}_{4} \mathrm{C}_{1}$ ). They show only slight decrease or even in some areas an increase in suitability of areas to produce beans with high flavor and acidity content.

\subsection{CaNaSTA and Maxent model performance}

MaxEnt performed well, with AUC (kappa) values $0.81(0.88)-0.84(0.91)$ for the test data (25\%), and almost no variation for the training data (75\%) (Figure S1). The good performance gave low baseline uncertainties.

CaNaSTA performed even better than MaxEnt, particularly for coffee acidity (Figure S2 und S3). For the test data AUC values for acidity were 0.989-0.993, whereas the test data $k_{\max }$ values were $0.957-0.98$. For flavor, test-data AUC and $k_{\max }$ values were $0.989-0.995$ and $0.932-0.98$, respectively. 


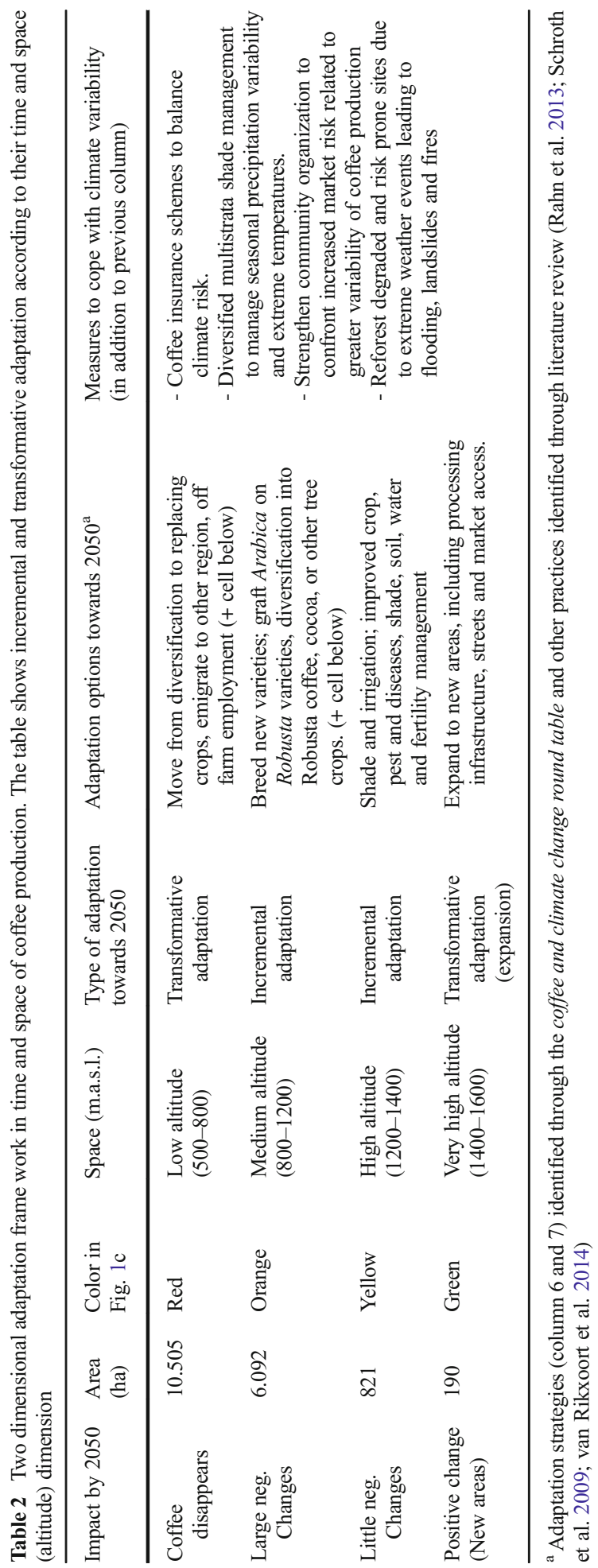




\subsection{Participatory expert round table and literature review}

The participatory workshop and literature review identified the most promising adaptation strategies responding to the four different impact scenarios (Table 2, column 6 and 7). For the impact scenario of positive suitability change a cautious expansion to new areas is recommended, for the scenario of little negative suitability change the implementation of good agricultural practices such as shade, irrigation, where feasible, and pest and disease management are recommended, for the scenario of large negative suitability changes new varieties and diversification to other tree crops is recommended and finally for the scenario of unsuitable locations (coffee disappears) diversification to other crops or livelihoods is recommended.

\section{Discussion}

\subsection{Impacts of climate change on suitability to grow coffee and coffee quality in Nicaragua}

Our MaxEnt model results indicate that coffee grows optimally at elevations between 800 and 1400 masl, but that this optimum will likely increase to 1200 and 1600 masl by 2050 . These results are consistent with what would be expected from the degree of warming $\left(\sim 2.5^{\circ} \mathrm{C}\right.$, see Fig. 2) and the adiabatic lapse rate $\left(0.65^{\circ} \mathrm{C}\right.$ per $\left.100 \mathrm{~m}\right)$.

CaNaSTA results also indicate that areas at higher altitudes (above 1500 masl) will likely become more suitable to produce high quality coffee with climate change. Importantly, there was a high likelihood that between today and 2050, areas at elevations between 500 masl and 1500 masl will suffer the greatest decrease in coffee suitability. According to our analyses, not only overall coffee production, but also coffee quality and the related PDO are likely to come under pressure as climatically suitable areas are likely to move up in altitude. Therefore, adaptation strategies need to consider practices and breeding of new varieties to maintain or increase production and quality while at the same time address disease and pest pressure.

This shift in elevation means that areas at high elevations will have similar climatic conditions in the future as those currently at lower altitudes'. Therefore, we argue that current management practices and strategies to manage climate risks at lower altitudes will very likely serve in the future at higher altitudes.

\subsection{Two-dimensional adaptation framework in space and time of coffee production}

The development of a two-dimensional adaptation framework in time and space is discussed using the results of climate suitability modeling and the identified adaptation strategies for coffee in Nicaragua. Uncertainties pertinent to planning of adaptation strategies for the long term compared with near term are likely to be different (Vermeulen et al. 2013). At lower levels of progressive climate change the climate signal may be indistinguishable from climate variability. Farmers can adjust by making incremental adaptation and innovations based on their experiences to deal with climate variability. Incremental adaptation implies that stakeholders adjust their decisions so that they can continue to meet current objectives under changed conditions (Stafford et al. 
2011). Examples are changing cultivars or management practices. However, at higher levels of progressive climate change, transformative adaptation is likely to be needed. This may include reconfiguration of one or more livelihoods, diets and geography of farming and food systems (Kates, et al. 2012; Rickards 2012). Transformative adaptation, therefore, refers to fundamental changes in objectives (Stafford et al. 2011), such as changing livelihoods, including moving to another industry or another region.

We used the concept of adaptation across time scales (Rickards 2012; Vermeulen et al. 2013) to provide specific recommendations for coffee-growing areas to adapt in time and space. We call this a two-dimensional adaptation framework in space and time of coffee production (Table 2). We identified four major impact scenarios by 2050 for coffee in Nicaragua (see Table 2, Figs. 2 and 3) according to the elevation of the growing zones and their recommended adaptation strategies:

- Low elevations (500-800 masl), where coffee disappears and transformational adaptation is recommended (e.g. replacement of Arabica coffee by Robusta coffee or cocoa);

- Medium elevation (800-1200 masl), where large negative changes are projected and incremental adaptation is recommended (e.g. new varieties and diversification);

- High elevations (1200-1400 masl), where little negative changes are projected and incremental adaptation is recommended (e.g. shade and irrigation); and

- Very high elevations (1400-1600 masl), where positive changes are projected and transformational adaptation is recommended (e.g. expansion into new areas).

Our analysis of adaptation indicates that incremental adaptation occurs in a short timeframe at lower altitudes, whereas the same areas may undergo transformative adaptation in the long term. At higher altitudes incremental adaption may be needed in the long term. The same principle and framework is applicable across coffee growing regions around the world, as the patterns of decreasing exposure with higher altitudes are the same globally (Ovalle-Rivera et al. 2015); only the magnitude and timeframe changes.

Although we did not analyze the effects of climate variability on coffee production, it is very important as shown, for example, by Avelino et al. (2015) for the case of climate variability, which was an important factor to trigger the coffee rust crisis in Colombia and Central America. We argue that in addition to the strategies listed in Table 2, strategies will be needed to cope with climate variability and changes in soil properties that result from land degradation and climate change. These strategies should be in place in all current growing areas and at all times. However, a better understanding of climate variability and its impacts on coffee production, as well as changes in soil properties under climate change is required.

\section{Conclusions}

Arabica coffee, which is highly sensitive to temperature, will be affected by climate change. By 2050 the suitability of areas to grow arabica coffee in Nicaragua will move approximately $300 \mathrm{~m}$ up the altitudinal gradient. Farmers at lower elevations will no longer be able to grow quality coffee and may have to abandon it. Moving to higher elevations may increase pressure on forests and natural resources at higher altitudes. Actors along the coffee supply chain will have to adapt to the changes that climate change will bring.

We applied the concept of adaptation across time and space to provide specific adaptation recommendations for coffee-growing areas at different elevations in Nicaragua. We identified 
four major impact scenarios and its related adaptation strategies. Incremental adaptation occurs over a short term horizon at lower altitudes, whereas the same areas may undergo transformative adaptation in the long term. At higher altitudes incremental adaptation may be needed in the long term. Furthermore, strategies to cope with the impact of climate variability on coffee production should be in place in all growing areas now and for the future. The developed frame work is readily applicable across other coffee growing regions, as those regions will likely experience similar climatic impacts.

Acknowledgments This research was conducted under the CGIAR Research Program on Climate Change, Agriculture and Food Security (CCAFS).

Open Access This article is distributed under the terms of the Creative Commons Attribution 4.0 International License (http://creativecommons.org/licenses/by/4.0/), which permits unrestricted use, distribution, and reproduction in any medium, provided you give appropriate credit to the original author(s) and the source, provide a link to the Creative Commons license, and indicate if changes were made.

\section{References}

Avelino J, Cristancho M, Georgiou S, Imbach P, Aguilar L, Bornemann G, Läderach P, Anzueto F, Hruska AJ, Morales C (2015) The coffee rust crises in Colombia and central America (2008-2013): impacts, plausible causes and proposed solutions. 7:303-321. doi:10.1007/s12571-015-0446-9

Baca M, Läderach P, Haggar J, Schroth G, Ovalle O (2014) An integrated framework for assessing vulnerability to climate change and developing adaptation strategies for coffee growing families in Mesoamerica. doi:10. 1371/journal.pone.0088463

Barbet-Massin M, Jiguet F, Albert CH, Thuiller W (2012) Selecting pseudo-absences for species distribution models: how, where and how many? Methods Ecol. Evol 3:327-338

Bunn C, Läderach P, Ovalle Rivera O, Kirschke D (2014) A bitter cup: climate change profile of global production of Arabica and Robusta coffee. Clim Chang 129:89-101

Busby JR (1991) A bioclimatic analysis and prediction system. In: Margules CR, Austin MP (eds) Nature conservation: cost effective biological surveys and data analysis. CSIRO, Australia pp 64-68

CCAFS-Climate-Portal (2016) http://ccafs-climate.org.

CEPAL (2011) La economía del cambio climático en Centroamérica. CEPAL, Mexico. http://www.cepal.org/es/ publicaciones/26058-la-economia-del-cambioclimatico-en-centroamerica-reporte-tecnico-2011

Challinor AJ, Wheeler TR, Slingo JM, Hemming D (2005) Quantification of physical and biological uncertainty in the simulation of the yield of a tropical crop using present-day and doubled CO2 climates. Philos Trans R Soc B: Biol Sci 360:2085-2094

Craparo ACW, Van Asten PJA, Läderach P, Jassogne LTP, Grab SW (2015) Coffea arabica yields decline in Tanzania due to climate change: Global implications. Agric For Meteorol 207:1-10

Davis APGT, Baena S, Moat J (2012) The impact of climate change on indigenous arabica coffee (Coffea arabica): predicting future trends and identifying priorities. PLoS One 7(11):e47981. doi:10.1371/journal. pone.0047981

Elith* J, Graham* CH, Anderson RP, Dudík M, Ferrier S, Guisan A, Hijmans RJ, Huettmann F, Leathwick JR, Lehmann A, Li J, Lohmann LG, Loiselle BA, Manion G, Moritz C, Nakamura M, Nakazawa Y, Overton JMM, Townsend Peterson A, Phillips SJ, Richardson K, Scachetti-Pereira R, Schapire RE, Soberón J, Williams S, Wisz MS, Zimmermann NE (2006) Novel methods improve prediction of species' distributions from occurrence data. Ecography 29:129-151. doi:10.1111/j.2006.0906-7590.04596.x

Fielding AH, Bell JF (1997) A review of methods for assessment of prediction errors in conservation presence/ absence models. Environ Conserv 24(1):38-49

FUNICA (2012) Informe Anual 2012. Fundación para el desarrollo tecnológico, agropecuario y forestal de Nicaragua. http://funica.org.ni/index/informacion-publica/category/38-informes-anuales.html?download= 591:InformeAnual2012

Garcia LJ, Posada-Suarez H, Läderach P (2014) Recommendations for the regionalizing of coffee cultivation in Colombia: a methodological proposal based on agro-climatic indices. PLoS One 9:e113510

Giorgi F (2006) Climate change hot-spots. Geophys Res Lett 33:1-4. doi:10.1029/2006GL025734 
Gourdji S, Läderach P, Valle AM, Martinez CZ, Lobell DB (2015) Historical climate trends, deforestation, and maize and bean yields in Nicaragua. Agric For Meteorol 200:270-281

Hijmans RJ, Cameron SE, Parra JL, Jones PG, Jarvis A (2005) Very high resolution interpolated climate surfacesfor global land areas. Int J Climatol 25:1965-1978. doi:10.1002/joc.1276

ICO (2013) Statistics on coffee: historical production data worldwide. In Organization ICO (ed.) Retrieved July, 2016, from: http://www.ico.org/trade_statistics.asp

IPCC (2014) AR4 GCM data. http://www.ipcc-data.org/sim/gcm monthly/SRES AR4/index.html

Jha S, Bacon CM, Philpott SM, Ernesto Mendez V, Läderach P, Rice RA (2014) Shade coffee: update on a disappearing refuge for biodiversity. Bioscience 64:416-428

Kates RW, Travis WR, Wilbanks TJ (2012) Transformational adaptation when incremental adaptations to climate change are insufficient. Proc Natl Acad Sci U S A 109(19):7156-7161

Knutti R, Sedlacek J (2012) Robustness and uncertainties in the new CMIP5 climate model projections. Nature Clim 3:369-373. doi:10.1038/nclimate1716

Kreft S, Eckstien D (2013) Global climate risk index 2014: who suffers most from extreme weather events? Weather-related loss events in 2012 and 1993 to 2012. Bonn, Germany

Läderach P, Oberthür T, Cook S, Estrada Iza M, Pohlan JA, Fisher M, Rosales Lechuga R (2011) Systematic agronomic farm management for improved coffee quality. Field Crop Res 120:321-329

Läderach P, Martinez A, Schroth G, Castro N (2013) Predicting the future climatic suitability for cocoa farming of the world's leading producer countries, Ghana and Côte d'Ivoire. Clim Chang 119:841-854. doi:10.1007/ s10584-013-0774-8

Lingle TR (2001) The coffee cuppers' handbook - a systematic guide to the sensory evaluation of coffee's flavor. Specialty coffee Association of America, Third edn. Long Beach, California

Liu C, Berry PM, Dawson TP, Pearson RG (2005) Selecting thresholds of occurrence in the prediction of species distributions. Ecography (Cop) 28:385-393

Lobo JM, Jiménez-Valverde A, Real R (2008) AUC: a misleading measure of the performance of predictive distribution models. Glob Ecol Biogeogr 17:145-151

MAGFOR (MAG - Agricultural Ministry of Nicaragua) (2013) El Café en Nicaragua. Retrieved July, 2016, from: http:/www.magfor.gob.ni/descargas/publicaciones/cafecacao/cafenicaragua.pdf

Manel S, Williams HC, Ormerod SJ (2001) Evaluating presence-absence models in ecology: the need to account for prevalence. J Appl Ecol 38:921-931

O'Brien K, Eriksen S, Schjolden A, Nygaard L (2004) What's in a word? Conflicting interpretations of vulnerability in climate change research. Center for International Climate and Environmental Research CICERO, pp. 1-19

Oberthür T, Läderach P, Posada H, Fisher MJ, Samper LF, Illera J, Collet L, Moreno E, Alarcón R, Villegas A, Usma H, Perez C, Jarvis A (2011) Regional relationships between inherent coffee quality and growing environment for denomination of origin labels in Nariño and Cauca, Colombia. Food Policy 36:783-794. doi:10.1016/j.foodpol.2011.07.005

Ovalle-Rivera O, Läderach P, Bunn C, Obersteiner M, Schroth G (2015) Projected shifts in Coffea arabica suitability among major global producing regions due to climate change. doi:10.1371/journal.pone.0124155

Peterson AT, Papes M, Soberón J (2008) Rethinking receiver operating characteristic analysis applications in ecological niche modeling. Ecol Model 213:63-72

Phillips SJ, Dudík M (2008) Modeling of species distributions with Maxent: new extensions and a comprehensive evaluation. Ecography 31:161-175. doi:10.1111/j.0906-7590.2008.5203.x

Phillips SJ, Anderson RP, Schapire RE (2006) Maximum entropy modeling of species geographic distributions. Ecol Model 190:231-259

Rahn E, Läderach P, Baca M, Cressy C, Schroth G, Malin D, van Rikxoort H, Shriver J (2013) Climate change adaptation, mitigation and livelihood benefits in coffee production: where are the synergies? Mitig Adapt Strateg Glob Chang 19:1119-1137

Ramírez J, Jarvis A (2010) Downscaling global circulation model outputs: the delta method in (CIAT). DaPAwpICfTA (ed.) Decision and policy analysis working paper No. 1

Rickards LHS (2012) Transformational adaptation: agriculture and climate change. Crop Pasture Sci 63(3):240-250

Schroth G, Läderach P, Dempewolf J, Philpott S, Haggar J, Eakin H, Castillejos T, Garcia Moreno J, Soto Pinto L, Hernandez R, Eitzinger A, Ramirez-Villegas J (2009) Towards a climate change adaptation strategy for coffee communities and ecosystems in the sierra Madre de Chiapas, Mexico. Mitig Adapt Strateg Glob Chang 14:605-625

Schroth G, Läderach P, Martinez-Valle AI, Bunn C, Jassogne L (2016a) Vulnerability to climate change of cocoa in West Africa: patterns and opportunities and limits to adaptation. Sci Total Environ 556:231-241

Schroth G, Läderach P, Martinez-Valle AI, Bunn L (2016b) From site-level to regional adaptation planning for tropical commodities: cocoa in West Africa. Mitig Adapt Strateg Glob Chang. doi:10.1007/s11027-0169707-y 
SRES I (2000) Special report on emissions scenarios: a special report of working group III of the intergovernmental panel on climate change. in Nakićenović N, R Swart eds, Cambridge University Press, UK. 570 pp. http://www.ipcc.ch/ipccreports/sres/emission/index.php?idp=0

Stafford MHL, Harvey A, Hamilton C (2011) Rethinking adaptation for a $4{ }^{\circ} \mathrm{C}$ world 2010. Philos Trans R Soc 369(1934):196-216

Valerio-Hernández L (2002) Elaboración del Mapa del Cultivo de Café de Nicaragua. in Informe Final. Dirección General de Estrategias Territoriales. Ministerio Agropecuario y Forestal. Managua N (ed.)

van Rikxoort H, Schroth G, Läderach P, Rodríguez-Sánchez B (2014) Carbon footprints and carbon stocks reveal climate-friendly coffee production. Agron Sustain Dev 34:887-897

VanDerWal J, Shoo LP, Graham C, Williams SE (2009) Selecting pseudo-absence data for presence-only distribution modeling: how far should you stray from what you know? Ecol Model 220:589-594

Vermeulen S, Challinor AJ, Thornton PK, Campbell BM, Eriyagama N, Vervoort JM, Kinyangi J, Jarvis A, Läderach P, Ramirez-Villegas J, Nicklin KJ, Hawkins E, Smith DR (2013) Addressing uncertainty in adaptation planning for agriculture. PNAS 110:8357-8362. doi:10.1073/pnas.1219441110

Waller JM, Bigger M, Hillocks RJ (2007) World coffee production. Coffee pests, diseases and their management. CABI, Wallingford, pp. 17-33

Wardle DA, Bardgett RD, Callaway RM, Van der Putten WH (2011) Terrestrial ecosystem responses to species gains and losses. Science 332:1273-1277

Warren DL, Seifert SN (2011) Ecological niche modeling in Maxent: the importance of model complexity and the performance of model selection criteria. Ecol Appl 21:335-342

Whitsed R, Läderach P, Corner R, Collet L, Cook S, Peters M, Cock J, Oberthür T (2010) Crop niche selection for tropical agriculture CaNaSTA. Version 1.0. Method, manual and case studies. Verlag Dr Müller, Saarbrueck

Whitsed R, Corner R, Cook S (2011) A model to predict ordinal suitability using sparse and uncertain data. Appl Geogr 32:401-408

WorldClim Global Climate Data (2015) http://www.worldclim.org/bioclim 